\title{
Restlessness, CTCAE
}

National Cancer Institute

\section{Source}

National Cancer Institute. Restlessness, CT CAE. NCI Thesaurus. Code C143811.

A disorder characterized by an inability to rest, relax or be still. 